\title{
MANUFACTURE OF HIGHLY ANTIOXIDANT LOW CALORIES BEVERAGES AND ICES FROM FERMENTED MILK PERMEATE \\ Moustafa, Karima A. ${ }^{1}$; Nagla A. Hegazi ${ }^{1}$ and M.A. El-Nawawy ${ }^{2}$ ${ }^{1}$ Dairy Research Department, Animal Production Research Institute, Agric. Res. Center, Dokki, Giza, Egypt \\ ${ }^{2}$ Food Science Dept., Faculty of Agric., Ain Shams Univ., Cairo, Egypt
}

\begin{abstract}
Highly antioxidant low calories beverages and ices were made using fermented milk permeate. Milk permeate was heated at $80 \circ \mathrm{C}$ for $10 \mathrm{~min}$, cooled to 30

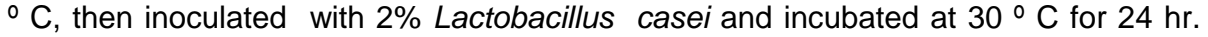
The fermented milk permeate was then used for the manufacture of beverages and ices. Sugar (sucrose) as the control was used to sweeten the products while low calories sweeteners like natreen, sweetline and steviapura were added in equivalence to the control.

Fermented permeate fruit beverages were prepared using fermented permeate and fruit juices in different concentration: $43 \%$ cantaloupe, $33 \%$ guava, $55 \%$ pomegranate and $33 \%$ kumquat. Sugars (sucrose) added were $12 \%$ for cantaloupe, guava and pomegranate while, it was $15 \%$ for kumquat. Pectin $(0.3 \%)$ was added in all treatments. $\mathrm{pH}$ value, color index, total sugars, phenol content and $\beta$-carotene were determined fresh and after 7 days and 14days of storage at $4 \stackrel{\circ}{\mathrm{C}}$. Lactic acid bacterial counts (LAB) were also determined during storage. Sensory evaluation indicated higher total scores for fresh fruit beverages than the stored ones in all fruit beverages and in all treatments.

Fermented permeate fruit ices were prepared by using fermented permeate and fruit juices in different concentrations: $43 \%$ cantaloupe, $15 \%$ apricot and $20 \%$ kumquat. The control was $20 \%$ sugar for cantaloupe ice, $15 \%$ for apricot ice and $25 \%$ for kumquat ice. Pectin (0.3\%) was added in all treatments. In the ice mixtures and ices, total solids, $\mathrm{pH}$ value, specific gravity and weight per kilogram were determined. Freezing point and viscosity were measured in ice mixtures, while overrun and melting resistance in fruit ices. Sensory evaluations were carried out revealing no differences between the different sweeteners used among the same fruit. The control gained a little higher scores than all the other sweeteners.

It is recommended that the presence of low calories fruit beverages and ices in the market could be of great benefit for the people of special requirements like obese and diabetes.

Keywords: Fermented milk permeate, L. casei, fermented fruit beverages, fermented fruit ices, kumquat, guava, cantaloupe, pomegranate, apricot, low calories, antioxidant.
\end{abstract}

\section{INTRODUCTION}

Milk permeate is an aqueous solution removed from milk by ultrafiltration process .It consists of $5 \%$ total solids, $90 \%$ of which is lactose, and is fat free. Milk permeate is rich in minerals, vitamins and some amino acids not found in substitute ingredients and enhances the overall nutritional content of food products. Thus milk permeate could be used in the manufacture of some food products such as ice-creams, cooked products, bakery blends, fermented beverages ...etc., or utilized in the production of 
many useful products such as lactic acid, polyhydroxy alkanoate, gluconic acid , citric acid ...etc. (Abd El-Khair, 2009).

Milk permeate is a problem for environmental pollution. However, because of its high organic content its disposal can pose environmental problems. Milk permeate shows a very high COD value (Chemical Oxygen Demand) about $60,000 \mathrm{mg} / \mathrm{l}$ and, therefore it cannot be drained without a treatment. Recently several uses have been proposed for utilization of permeate but still enormous quantities are left unutilized.

The human body is continually exposed to free radicals which are implicated in the initiation and progression of number of diseases. Antioxidants are known to protect tissues against the damaging effects of oxygen free radicals. Therefore, it has been hypothesized that a diet rich in antioxidants may infer protection against certain diseases (Dembinska-Kiec et al., 2008).

Fruits and vegetables are a major source of antioxidants amongst other bioactive compounds essential for optimal health. The most abundant antioxidants in fruits are polyphenols, Vitamin $C$, Vitamin $A, B$ and $E$, and carotenoids which are present to a lesser extent in some fruits. The polyphenols, most of which are flavonoids, are present mainly in ester and glycoside forms (Blomhoff, 2005). However, though lacking in the fiber content of whole fruits, fruit juices are an excellent source of antioxidants (Seeram et al., 2008 and Tezcan et al., 2009). Recently there has been extensive research into the production of different products which have high antioxidant capacity of fruit juices. El- Sayed et al.(2007), Abd El-Khair (2009), Aboel Einen et al.( 2009) and Hegazi et al.( 2009) used milk permeate fortified with different fruit juices, as natural sources of antioxidants, to produce functional ices and beverages.

Lactobacilli were the first bacterial genus suspected to have health benefits (Stanton et al.,2003). L.casei as a microbe used as probiotic and its documented health benefits in human clinical trials was adapted from (Ouwehand et al. (2002)). Probiotics fall into the functional food category, which is an expending sector of the food industry (Stanton et al., (2001). On that basis, fermentation of the permeate by $L$. casei prior to the addition of the fruit juices was our technique.

Nowadays, consumption of reduced calorie sugar has become a permanent of modern lifestyle ( Abd El-ghany, 2008). The food industry has recently focused on the possible use of low calorie sweeteners as sugar substitutes in variable products in order to provide the need for persons of special requirements, i.e. athletes, diabetic, obese and other diseases.

The present market is now being driven by enhanced awareness among consumers of the role of diet in health maintenance and diseases prevention, and so the goal of the present paper is to share in the presence of highly antioxidant low calorie fruit beverages and ices from fermented milk permeate in our local market. 


\section{MATERIALS AND METHODS}

Fresh buffalo milk permeate was obtained from the Unit of Milk Industry ,Animal Production Research Institute, Agriculture Research Center, Giza, Egypt. Milk permeate contained: $4.1 \%$ lactose, $0.6 \%$ nitrogen substances, $0.5 \%$ various minerals and was fat free. Its $\mathrm{pH}$ was 6.6

Apricot (Prunus armeniaca), cantaloupe (Cucumis melo), kumquat (Fortunella margarita), pomegranate (Punica granatum) and guava (Psidium guajava) were obtained from hyper supermarkets in Cairo and their constituents were analysed according to AOAC (2007)

Sugar was obtained from the local market. Natreen and sweet line (are synthetic sweeteners which contained a mixture of sodium cyclamate E952 and sodium saccharine E954) and steviapura (which is a natural sweetener in form of steviol glycosides E960) were used as the sweeteners to prepare the low calories fermented permeate beverages and ices. Natreen was obtained from Sara Lee GmbH, Köln, Germany; sweet line was obtained from Rossmann $\mathrm{GmbH}$, Burgwedel, Germany; and steviapura was from Stevia group, Koeln, Germany. All sweeteners are permitted as food additives according to Codex Stan 192-1995(2011) and the American and European regulations. Denmark.

L. casei culture was obtained from Chr. Hansen Lab., Copenhagen,

Apricots were cleaned, seeds were discarded and soft fruits were blended. Cantaloupe was peeled, seeds were discarded, and the soft fruit was cut into pieces then blended. Pomegranate was peeled to collect the arils from the pulp then the arils were squeezed to remove the seeds. Guava was cleaned and blended then the juice was sieved to remove the seeds. The juices of the four fruits were heat treated at $80 \circ \mathrm{C}$ for $10 \mathrm{~min}$. Kumquat was cleaned then the interior seeds were removed from each one. Kumquat fruits were boiled until its tissues were tender then blended to get juice. All fruit juices were stored at $-20 \stackrel{\circ}{C}$ until use. The chemical composition of the fruit juices are shown in Table (1).

Table(1):Chemical composition* of the prepared fruit juices used in this study (per100g)

\begin{tabular}{|c|c|c|c|c|c|c|c|c|}
\hline Fruit & $\begin{array}{c}\text { Moisture } \\
(\mathbf{\%})\end{array}$ & $\begin{array}{c}\text { Total } \\
\mathbf{s u g a r} \\
(\mathbf{g})\end{array}$ & $\begin{array}{c}\text { Protein } \\
(\mathbf{g})\end{array}$ & $\begin{array}{c}\text { Fat } \\
(\mathbf{g})\end{array}$ & $\begin{array}{c}\text { Ash } \\
(\mathbf{g})\end{array}$ & $\begin{array}{c}\text { Carotenes } \\
(\mathbf{I U )}\end{array}$ & $\begin{array}{c}\text { Total } \\
\text { phenols } \\
(\mathbf{m g})\end{array}$ & $\begin{array}{c}\text { Flavon- } \\
\text { oinds } \\
(\mathbf{m g})\end{array}$ \\
\hline Apricot & 86.12 & 9.42 & 1.43 & 0.31 & 0.45 & 350 & 140 & 100 \\
\hline Cantaloupe & 89.23 & 6.84 & 1.75 & 0.15 & 0.42 & 189 & 240 & 110 \\
\hline Guava & 83.21 & 8.34 & 1.0 & 0.51 & 0.53 & 120 & 210 & 80 \\
\hline Kumquat & 88.32 & 5.42 & 1.55 & 0.64 & 0.32 & 200 & 120 & 100 \\
\hline Pomegranate & $\mathbf{8 6 . 4 2}$ & $\mathbf{1 2 . 5}$ & $\mathbf{0 . 8 5}$ & $\mathbf{0 . 3 1}$ & $\mathbf{0 . 6 7}$ & $\mathbf{7 5}$ & $\mathbf{4 8 0}$ & $\mathbf{2 6 0}$ \\
\hline
\end{tabular}

*Determined according to AOAC (2007)

The milk permeate was heat treated at $80 \cong \mathrm{C}$ for $10 \mathrm{~min}$ and cooled suddenly to $30{ }^{\circ} \mathrm{C}$, inoculated with $2 \%$ of $L$. casei and incubated at $30{ }^{\circ} \mathrm{C}$ for 
24 hours. The fermented permeate was divided into two batches for manufacture of the ices and beverages.

Preliminary experiments were carried out to determine the most favorable concentration of both juice and sugar for each type of fruit juices. The first batch of the fermented permeate was divided into four portions. Each portion was used to prepare a type of fruit beverage. The percentages of fruit juices, which were cantaloupe, pomegranate, guava and kumquat, and the sugar used for the preparation of the fermented beverages are shown in Table (2).

Natreen, sweet line and steviapura were added individually in equivalence to the desired sweet taste as the preliminary tests indicated for sugar. Pectin $(0.3 \%)$ was added in all treatments. The resultant fermented beverages were filled into $200 \mathrm{ml}$ brown bottles, stored at $4 \stackrel{\circ}{\mathrm{C}}$ and analyzed at fresh, 7 and 14 days. All treatments were in triplicates.

Table (2): Composition of the control fermented permeate beverages.

\begin{tabular}{|l|c|c|c|c|}
\hline Ingredients \% & Cantaloupe & Guava & Pomegranate & Kumquat \\
\hline Juice & 43 & 33 & 55 & 33 \\
\hline Sugar & 12 & 12 & 12 & 15 \\
\hline Pectin & 0.3 & 0.3 & 0.3 & 0.3 \\
\hline $\begin{array}{l}\text { Fermented } \\
\text { permeate }\end{array}$ & 44.7 & 54.3 & 32.7 & 51.7 \\
\hline Total weight & 100 & 100 & 100 & 100 \\
\hline
\end{tabular}

For the preparations of the fermented permeat ice mixtures, the second batch of the fermented permeate was divided into three parts. Taking into consideration the desirable fruit juices and sugar concentrations in pilot tests, the ice mixtures were manufactured according to Marsall et al. (2003), as shown in Table (3).

Natreen, sweet line and steviapura sweeteners were added in equivalence to the desired sugar concentration taste which were considered as the control. Pectin $(0.3 \%)$ was added in all treatments.

The freezing of the ice mixture was conducted by an electrically ice cream freezer. When the product became semi frozen, it was packed in polystyrene

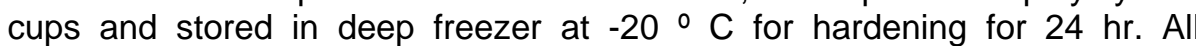
treatments were repeated five times.

Table (3): Composition of the control fermented permeate ice mixtures.

\begin{tabular}{|l|c|c|c|}
\hline Ingredients \% & Cantaloupe & Apricot & Kumquat \\
\hline Juice & 43 & 15 & 20 \\
\hline Sugar & 20 & 25 & 25 \\
\hline Pectin & 0.3 & 0.3 & 0.3 \\
\hline Fermented permeate & 36.7 & 57.7 & 54.7 \\
\hline Total weight & 100 & 100 & 100 \\
\hline
\end{tabular}

The total solids, fat, protein and total sugars were determined according to AOAC (2007). $\mathrm{pH}$ value was measured by laboratory $\mathrm{pH}$ - 
meter(Jenway $3505 \mathrm{pH}$ meter). The total phenolic compounds and carotenoids were determined according to Prieto et al. (1999).

In beverages the colors index were determined using Shimadsu UV 240 Spectrophotometer at $550 \mathrm{~nm}$ for pomegranate beverage, $555 \mathrm{~nm}$ for guava and cantaloupe beverages and $575 \mathrm{~nm}$ for kumquat beverage.

In ices the specific gravity tests of both mix and ice were measured by using pyconometer as described by Winton (1958) at $20 \circ \mathrm{C}$. The weight per kilogram of both mix and frozen fermented ices was determined according to Burke (1947) with a slight modification in which the specific gravity was multiplied by the factor 3.7853 to give the weight per gallon in kilograms. Freezing point was determined using specific thermometer. Viscosity was measured fresh and after $24 \mathrm{hrs}$ at $20 \cong \mathrm{C}$ and 60 r.p.m. using spindle no. 3 in Brookfild DV-E Viscometer,( Brookfild Engineering Laboratories, Inc, Middle boro, U.S.A.). Overrun was calculated according Marsall et al.(2003). Melting resistance of frozen ice was determined according to Ried and Painter (1933). Ices were placed in controlled cabined at $20 \cong \mathrm{C}$. The melted portions were weighed every $30 \mathrm{~min}$ for $2 \mathrm{hrs}$.

Lactic acid bacterial counts were determined fresh, and after 7 and after 14 days of storage using MRS agar media according to de Man et al. (1960). The plates were incubated at $30 \circ \mathrm{C}$ for $48 \mathrm{~h}$.

The sensory evaluation of the resultant beverages were assessed by the staff of the Dairy Departments, Animal Production Research Institute using the following score: flavor 50 points, color 25 points, appearance 25 points, and the total scores were 100. The resultant beverages were evaluated at fresh, 7 and 14 days of storage.

As with ices, the score was 50 for flavor, 40 for body and texture , and 10 for melting quality points and the total scores were 100 .

\section{RESULT AND DISCUSSION}

Fig (1) revealed the energy content of the highly antioxidant fermented permeate beverages of cantaloupe, guava, pomegranate and kumquate. The energy content was decreased in the treatments due to use of the sweeteners, which contained negligible calories, in the preparation of fruit beverages. Thus, the resultant products are considered low calories highly antioxidant fruit beverages.

Fig. (2) presented the $\mathrm{pH}$ values of the low calories highly antioxidant fermented beverages of cantaloupe, guava, pomegranate and kumquat during storage. It was noticed that the $\mathrm{pH}$ values of the low calories beverages were slightly higher than the control in cantaloupe, guava and kumquat beverages, while they were the same in pomegranate beverages. In general, all the $\mathrm{pH}$ values decreased in all treatments during storage which lasted for 14 days.

Values of the color index of cantaloupe and guava fermented beverages increased in all treatments at the end of storage period, while it decreased in all treatments of pomegranate and kumquat beverages as shown in Fig.(3). 
As expected, total sugars in the control of all fruit beverages were the highest, due to its sucrose content, while treatments with sweeteners revealed obvious low total sugars contents. A declination in total sugars appeared in the control in all fruit beverages when 14 days of storage were reached. The rate of decrease in total sugars appeared in treatments of sweeteners in different fruit beverages was lesser (Data not showed).

Sweetness is a determinant of thirst-quenching liking and amount of beverage consumption (Beucler et al., 2005). The presence of flavor and sweetness in a thirst-quenching beverage increased consumption in exercising individuals (Passe et al., 2000). In beverage liking, Beucler et al., (2005) indicated that higher sweetness intensity was undesirable for thirstquenching beverage. Our beverages, as low calories drinks possess health benefits to diabetic patients and those on diet.

The resultant low calories fermented fruit beverages revealed different values of total phenols and carotenoids. The phenol contents of the fermented fruit beverages differed from one to other when fresh due to the differences of its phenol content in the fruit juices and its added ratio. Generally, the control (sugar) of all fruit beverages contained the highest values of phenol at fresh and after 14 days of storage. From Fig. (4) it was clear that the use of the sweeteners ( natreen, sweet line and steviapura) decreased the phenol content in all the fruit beverages.

Following the same trend, the $\beta$ - carotene content (Fig. 5) of the fermented permeate fruit beverages had different values among the different fruit beverages. It could be noticed that the control, had the highest values of $\beta$ - carotene at fresh and after 14 days of storage in all the fruit beverages. Like phenol, the $\beta$ - carotene contents in all fruit beverages were affected by the addition of the sweeteners. Kumquat showed a very high $\beta$ - carotene value in its control beverage than the other beverage fruits.

In general, the total phenol and $\beta$ - carotene contents decreased during storage by using any type of sweeteners.

Fig.(6) showed the effect of sweetener type on the lactic acid bacterial counts (LAB) at fresh, 7 and 14 days of storage at $4{ }^{\circ} \mathrm{C}$ in the fermented permeate fruit beverages. The decrease in LAB counts was noticed in all the treatments with the advance in storage. Generally, it could be observed that the best survival of LAB counts during storage was noticed in the control of all different fruit beverages followed by the steviapura fruit beverage. The least LAB counts were detected in natreen fruit beverages.

In general, Fig (7) showed that the fresh fruit beverages scored higher total panel scores than the stored ones in different fruit beverages and in all treatments. Storage decreased the sensory scores in all treatments. In spite of the control (sucrose) gaining higher scores than the other sweeteners in all fruit beverages yet the differences were not considerable. It was also noticed that after 14 days of storage cantaloupe beverage gained the least panel sensory scores whereas kumquat beverage gained the highest. 

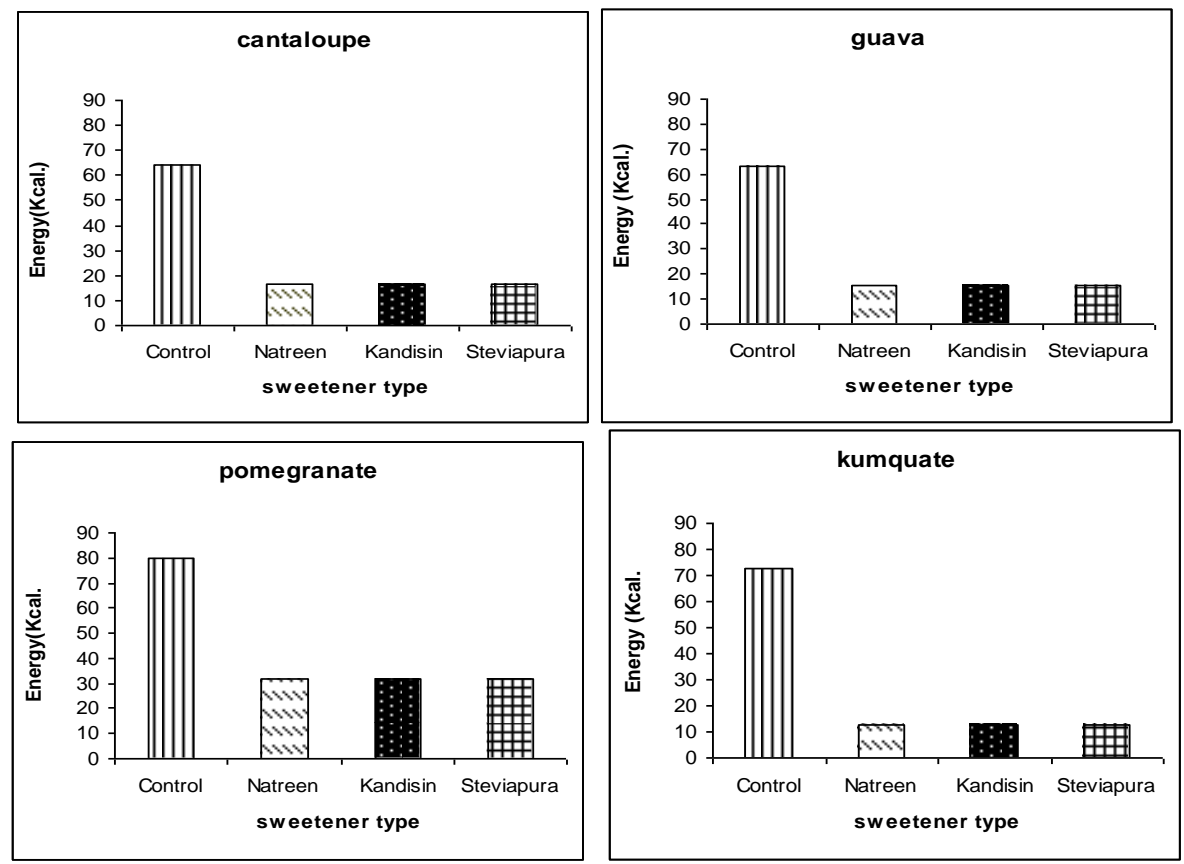

Fig. (1): Energy content (Kcal.) of the fresh fermented permeate fruit beverages.
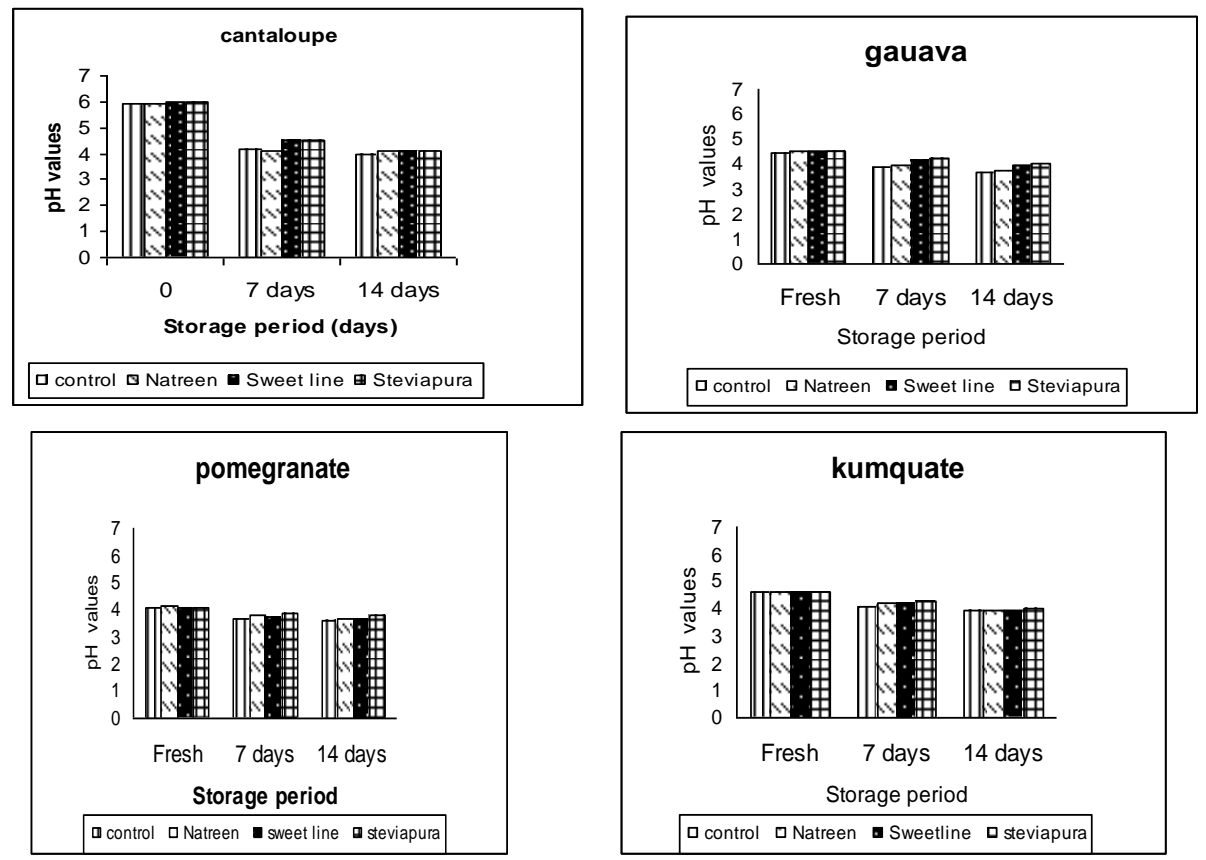
Moustafa, Karima A. et al.

Fig. (2): Effect of sweetener type on pH values of the fermented permeate fruit beverages during storage period (days) at $4^{\circ} \mathrm{C}$
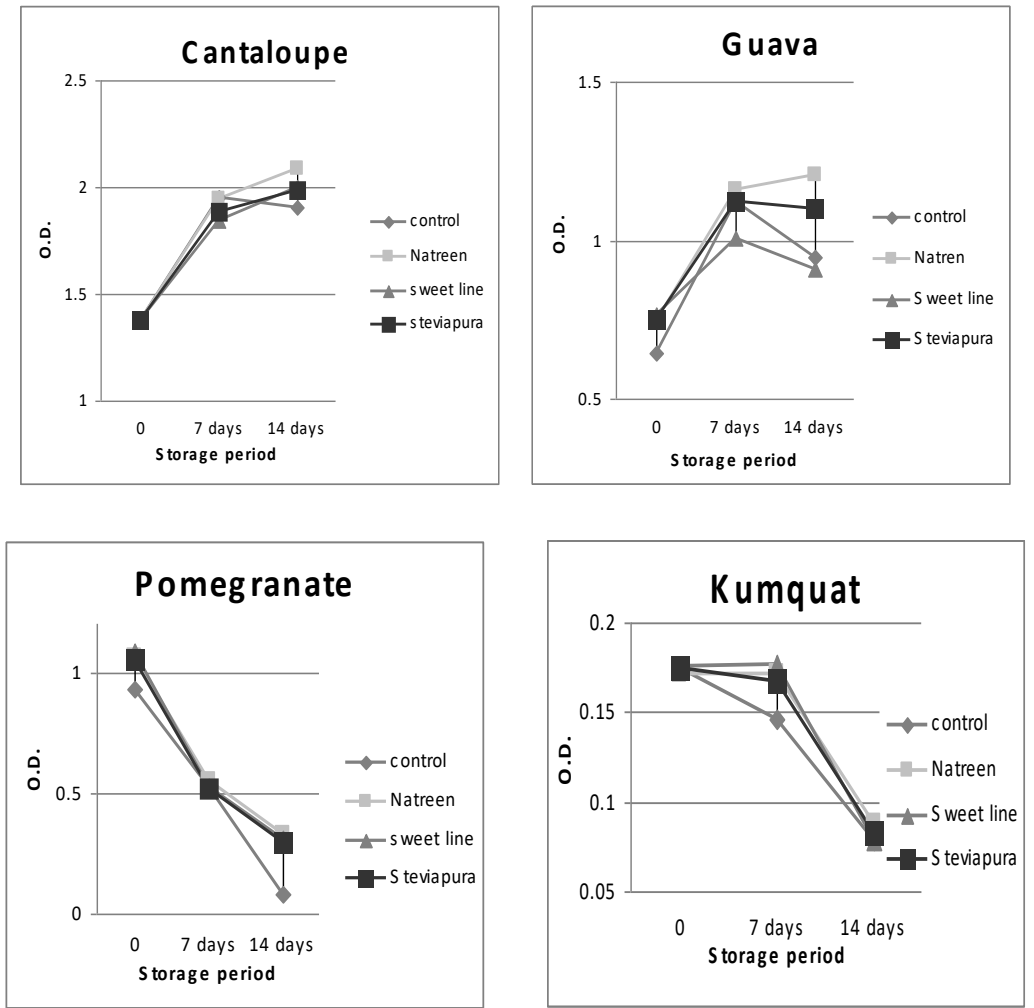

Fig. (3): Effect of sweetener type on the color index of the fermented permeate fruit beverages during storage period (days) at $4^{\circ} \mathrm{C}$

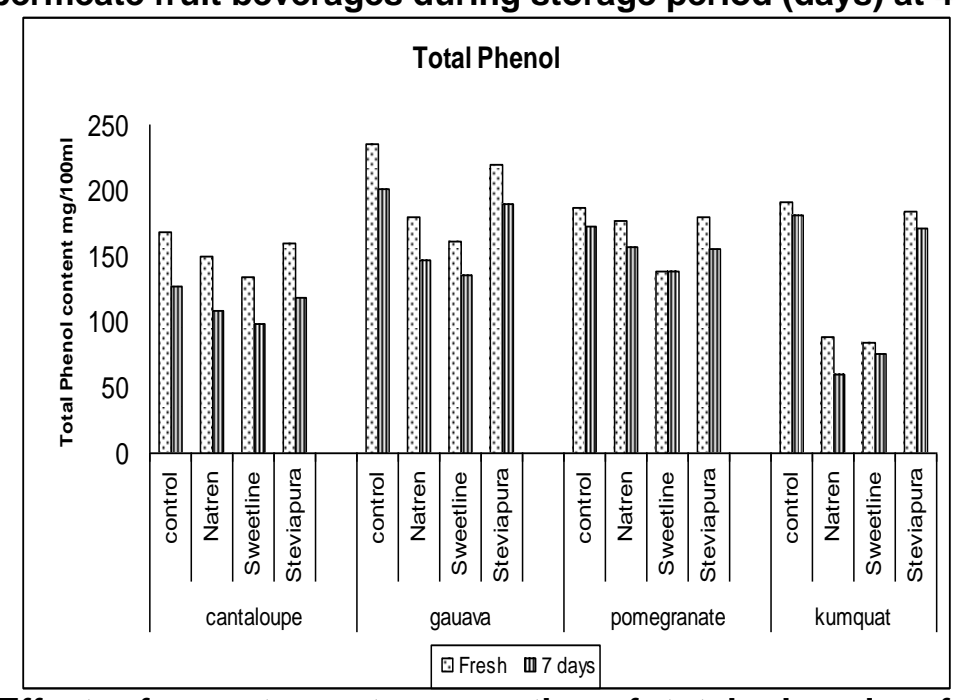

Fig. (4): Effect of sweetener type on the of total phenols of the 
fermented permeate fruit beverages during storage period (days) at $4^{\circ} \mathrm{C}$

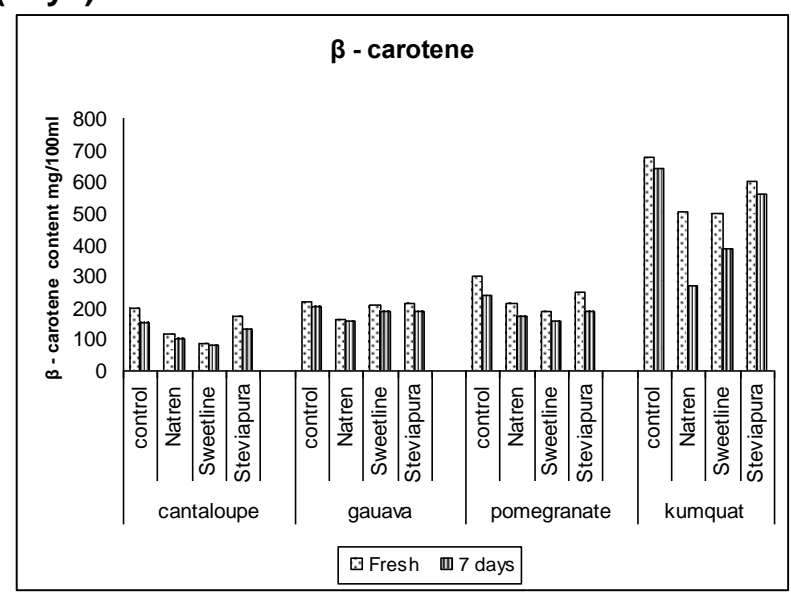

Fig (5): Effect of sweetener type on the of $\beta$ - carotene of the fermented permeate fruit beverages during storage period (days) at $4^{\circ} \mathrm{C}$
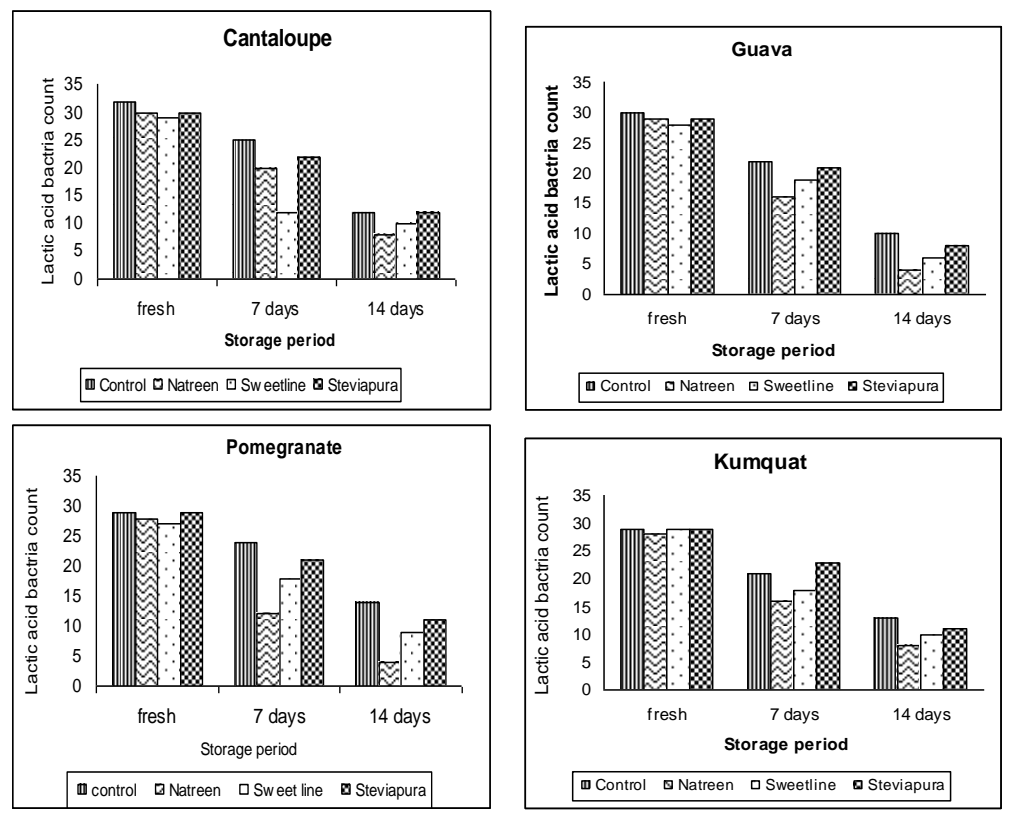

Fig. (6): Effect of sweetener type on the lactic acid bacterial counts ( $X$ $10^{8} \mathrm{cfu} / \mathrm{ml}$ ) of the fermented permeate fruit beverages during storage period (days) at $4^{\circ} \mathrm{C}$ 

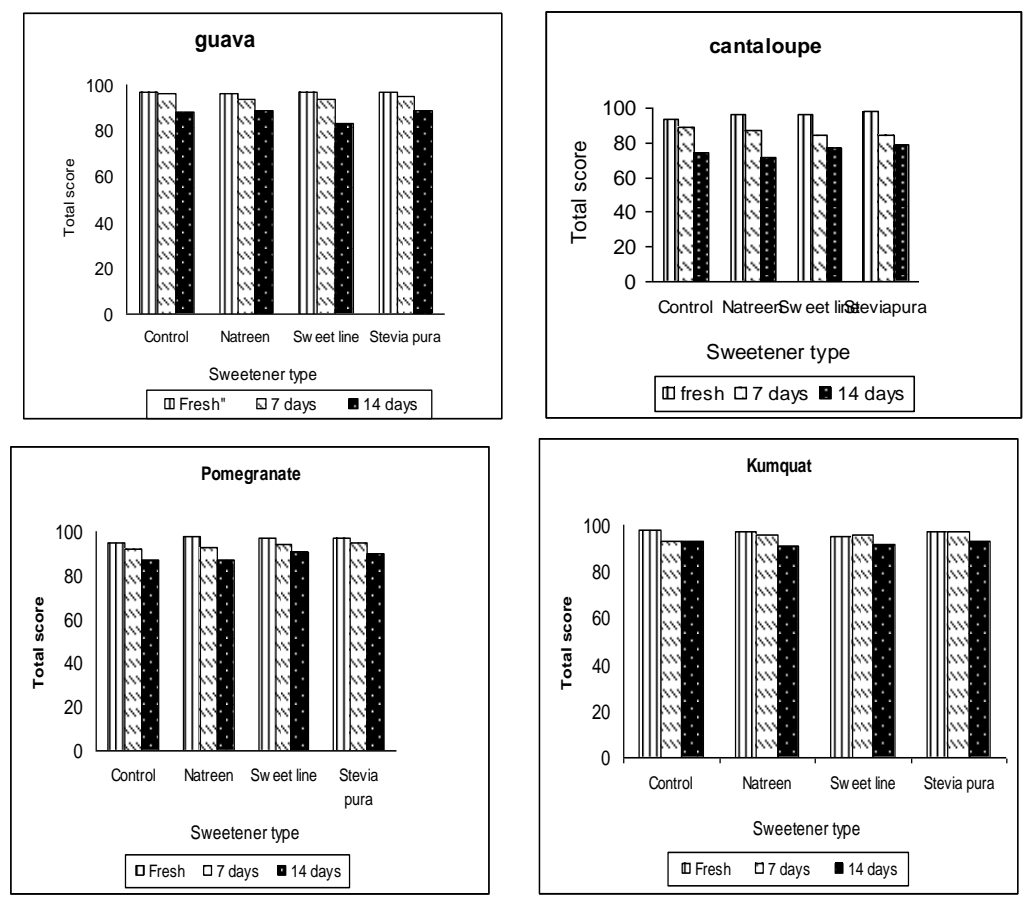

Fig. (7): Effect of sweetener type on the sensory evaluations of fermented permeate fruit beverages during storage at $4^{\circ} \mathrm{C}$

From the results in Table (4), it could be noticed that the total solids of the control of each fruit ice mix was greatly higher than all its sweetener treatments. This indeed is due to the presence of sucrose in the control. Marshall et al. (2003) mentioned that ices have a low total solids content compared to ice cream. The $\mathrm{pH}$ value in the control of each fruit ice mix was lesser than its treatments with different sweeteners.

The specific gravity and weight per kilogram in the control of each fruit ice mix were higher than the treatments of different sweeteners. The differences appeared between different sweetener types, i.e. natreen, sweet line and steviapura, in all the prepared mixes were not considerable.

The freezing points of the control of kumquat and apricot ice mixtures were reduced to $-6.3^{\circ} \mathrm{C}$, while it was $-6.4{ }^{\circ} \mathrm{C}$ in cantaloupe ice mix. All the sweetener treatments in all fruit mixes showed raising in its freezing points. An increase of -1.2 to $-2 \stackrel{\circ}{\circ}$ than the control clearly appeared in cantaloupe fruit mix. 
The viscosity of all the prepared ice mixtures increased after 24 hours of ageing. Generally, the control in all prepared fruit ice mixtures showed higher values than the treatments indicating the effect of sucrose on the viscosity. Same values of viscosity were gained at zero time (the start) and after 24 hours of ageing in kumquat and apricot ice mixes. Same trend, i.e. increase in viscosity, was observed in cantaloupe ice mix but with different values.

As with the Physicochemical Properties of the Resultant fruit Ice, It could be seen from Table ( 5 ), the total solids of the control of each fruit ice was obviously higher than all the sweetener treatments. The highest total solids values were noticed in apricot ice followed by kumquat ice then cantaloupe ice.

Slight or no difference in the $\mathrm{pH}$ values of the fruit ices between the control and its treatments were noticed. Cantaloupe ices had the highest $\mathrm{pH}$ values followed by kumquat ices then apricot ices.

Both the specifics gravity and weight per kilogram of all the controls of the different fruit ices were higher than its treatments with the different sweeteners.

From the results Table (5), the overrun (\%) values, as expected, were obviously high in all the control ices than its treatments. No obvious difference in the overrun $(\%)$ were observed when sweeteners were used with all fruits. Marshall et al . ( 2003 ) mentioned that sherbets which contain milk solids had low overrun ranging from 25-50\% while ices or water ices , which contain no milk solids, when frozen with from 0 ( quiescently frozen bars ) to $30 \%$ (dynamically frozen items ) overrun.

Melting resistance determine the loss in weight percent of the initial weight of the samples during 1.5 hours. The use of sweeteners, in different ice fruits, gave products that were hardener and melted more slowly than those made with equivalent sucrose content (controls). The melting resistance differed from one fruit ice to another, the most resistant was kumquat ice followed by cantaloupe then apricot ice. Slight differences were noticed between different types of sweeteners.

The energy contents were obviously higher in all the controls in all fruit ices than the treatments. due to the use of the sweeteners which contained negligible calories.

Sensory evaluation is an important indicator of consumer preference. Table (6) represents the effect of sweetener type on the sensory evaluation. It could be observed that no differences were noticed between the different types of sweeteners used, i.e. natreen, sweet line and steviapura, on the sensory evaluation among the same fruit ice. Generally, the control, i.e. using sucrose, gained little higher scores than all the sucrose replacements. In spite of the hard and coarse body and textures, yet the panel scores were reasonable because the panels were awarded that the samples were fruit ices and not fruit ice milks.

In conclusions, the fermented fruit beverages and ices showed a good source for nutraceutical food products and improved the cost benefit of milk permeate. 
Moustafa, Karima A. et al.

4

442 
J. Food and Dairy Sci., Mansoura Univ., Vol. 3 (7), July, 2012

5 
Moustafa, Karima A. et al. 


\section{REFERENCES}

Abd El- ghany,I.H.I. (2008). Production of low calorie ice- milk. 1- Using sucralose as sweetener. Egyptian J. Dairy Sci., 36:111-117

Abd El-Khair, A.A. (2009). Formulation of milk permeates for utilization as electrolyte beverages. Australian J. Basic Appl. Sci., 3: 572-578.

Abo El-einen, A.M.Karima; Hegazi, A.Nagla and El-Nawawy, M.A.(2009) Production of low calories functional ice permeate. J.Biol.Chem. Environ. Sci. 4:847-856.

AOAC (2007). Association of Official Analytical Chemists. Official Methods of Analysis 18th Ed. ,Washington, D.C ,USA.

Blomhoff, R. (2005). Dietary antioxidants and cardiovascular disease. Current Opinion in Lipidology. 16:47-54

Beucler, Janine; Drake, Maryanne and Foegeding, E.A. (2005). Design of a beverage from whey permeate J. Food Sci. 70:S277-S285.

Burke, A.D.(1947). Practical Ice Cream Making. Milwauke ,Wisconsin, U.S.A.

Codex Stan 192-1995(2011). Codex general standard for food additives, codex stan 192-1995

De Man , J.C.; Rogasa, M. and Sharp, M.E.(1960). A medium for the cultivation of lactobacilli. J. App. Bacteriol. 22:130

Dembinska-Kiec, A.; Mykka" nen, O.; Kiec-Wilk, B. and Mykka“" nen, H. (2008).Antioxidant phytochemicals against type 2 diabetes. British J. Nutrition, 99, ES109-ES117.

El-Sayed M.; Osama M. Abo-Salem,O.M.; Abd-Ellah,M.F.; Abd-Alla,G.M. (2007). Hesperidin an antioxidant flavonoid, prevents acrylonitrileinduced oxidative stress in rat brain . J. Egypt. Soc. Toxicol. Vol. 37: 87-93.

Hegazi, A.Nagla; AboelEinen,A.M. Karima and El-Nawawy, M.A.(2009). Production of low calories highly antioxidant thirst quenching fruit beverage using milk permeate. J. Biol. Sci. Environ. Sci., 4: 857-868.

Marshall, R. T.; Goff, H. D.and Hartel, R. W.(2003). Ice Cream. 6th ed Kluywer Academic/plenum publishers, New York.

Ouwehand, A.C., Salminen, S. and Isolauri, E. (2002) Probiotics: an overview of beneficial effects. Antonie Van Leeuwenhook 82, 279-289.

Passe, D.H.; Horn, M. and Murray, R. (2000). Impact of beverage acceptability on fluid intake during exercise. Appetite, 35: 219-229.

Prieto, P.; Pineda, M. and Aguilar, M. (1999). Spectrophotometric quantitation of antioxidant capacity through the formation of a phosphomolybdenum complex: Specific application to the determination of Vitamin E . Analytical Biochemistry. 269: 337-341.

Reid, W.H.E., and Painter, W.E., (1933). The freezing properties, stability and physical quality of chocolate ice cream. Missouri, Agr. Exp. Sta. Bull.18.

Seeram, N.P.; Aviram, M. and Zhang, Y. (2008). Comparison of the antioxidant potency of commonly consumed polyphenol-rich beverages in the United States. J. Agriculture and Food Chemistry, 56: 14151422. 
Stanton, C.; Gardiner, G.; Meehan, H.; Collins, K.; Fitzgerald, G.; Lynch, P.B. and Ross, R.P. (2001). Market potential for probiotics. Am. J. Clin. Nutr. 73(suppl.):476S-483S.

Stanton, C.; Desmond, C.; Fitzgerald, G. and Ross, R.P.(2003). Probiotic health benefits- reality or myth .Austr .J. Dairy Tech. vol. 58, No. 2:107113.

Tezcan, F.; Gu“" Itekin-Ozguven, M.; Diken, T.; Ozcelik, B. And Erim, F.B. (2009). Antioxidant activity and total phenolic , organic acid and sugar content in commercial pomegranate juices. Food Chemistry,115, 873877.

Winton,A.L.,(1958). Analysis of Foods. $3^{\text {rd }}$ Printing P.6. John Wiley and Sons Inc., New York.

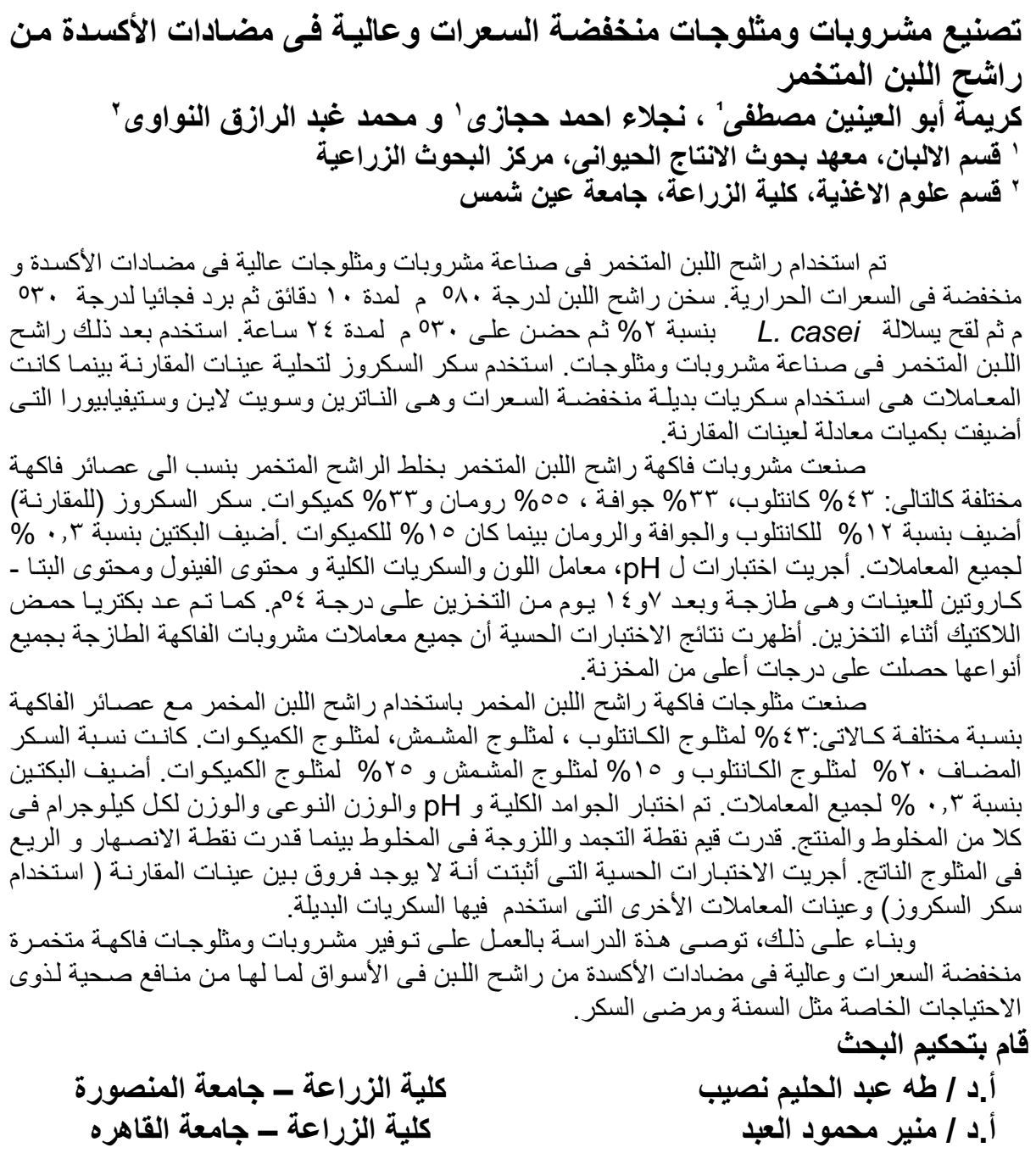


J. Food and Dairy Sci., Mansoura Univ., Vol. 3 (7), July, 2012 
J. Food and Dairy Sci., Mansoura Univ., Vol. 3 (7): 431 - 446, 2012

Table (4): Effect of sweetener type on the properties of the fermented permeate fruit ice mixtures

\begin{tabular}{|c|c|c|c|c|c|c|c|c|c|c|c|c|}
\hline \multirow[t]{2}{*}{ Properties } & \multicolumn{4}{|c|}{ Kumquat } & \multicolumn{4}{|c|}{ Apricot } & \multicolumn{4}{|c|}{ Cantaloupe } \\
\hline & Control & Natreen & $\begin{array}{c}\text { Sweet } \\
\text { line }\end{array}$ & $\begin{array}{l}\text { Stevia } \\
\text { pura }\end{array}$ & Control & Natreen & $\begin{array}{c}\text { Sweet } \\
\text { line }\end{array}$ & $\begin{array}{c}\text { Stevia } \\
\text { Pura }\end{array}$ & Control & Natreen & $\begin{array}{c}\text { Sweet } \\
\text { line }\end{array}$ & $\begin{array}{c}\text { Steviap } \\
\text { ura }\end{array}$ \\
\hline Total Solids & $r$. & $7, \ldots$ & $7, \ldots$ & 6.00 & $r$. & $7, \ldots$ & $7, \ldots$ & 6.0 & $r 0, \cdot 1$ & $7, .0$ & 0,91 & 6.0 \\
\hline $\mathrm{pH}$ & $\varepsilon, Y V$ & $\varepsilon, 70$ & $\varepsilon, 00$ & 4.60 & $\varepsilon, r V$ & $\varepsilon, 70$ & $\varepsilon, 00$ & 4.60 & $\varepsilon, 4 \vee$ & $\varepsilon, 8 \mathrm{~V}$ & $4.8^{\wedge}$ & 4.92 \\
\hline Specific Gravity & $\cdot, 971$ & $\cdot, \wedge \leqslant 0$ & $\cdot, 101$ & 0.853 & $\cdot, 971$ & $\cdot, \lambda \leqslant 0$ & $\cdot, 101$ & 0.864 & $1, .7 \varepsilon$ & $\cdot, 9 \wedge$. & $\cdot, 910$ & 0.953 \\
\hline $\begin{array}{c}\text { Weight per } \\
\text { Kilogram(W/K) }\end{array}$ & $\varepsilon, 1 \vee 4$ & $r, T \vee r$ & $r, 791$ & 3.643 & $\varepsilon, 1 \vee 4$ & $r, T V Y$ & $r, 79 \wedge$ & 3.694 & E,TKT & $\varepsilon, r \circ \Lambda$ & $\varepsilon, Y \wedge$. & 4.432 \\
\hline $\begin{array}{l}\text { Freezing } \\
\text { point }\left({ }^{\circ} \mathrm{C}\right)\end{array}$ & $-7, r$ & -0, & $-\varepsilon, 9$ & -5.0 & $-7, r$ & -0, & $-\varepsilon, 9$ & -5.0 & $-7, \varepsilon$ & $-0, Y$ & $-\varepsilon, \xi$ & -4.8 \\
\hline $\begin{array}{l}\text { Viscosity(C.P.) } \\
\text { Zero time }\end{array}$ & 14 & 1. & 1. & 10 & $1 \pi$ & 1 . & 1. & 10 & $\varepsilon, \varepsilon$ & $r, \varepsilon$ & $r, 0$ & 2.6 \\
\hline At 24 hours & 10 & $1 \pi$ & 14 & 13 & 10 & $1 \pi$ & $1 \pi$ & 13 & $V, \varepsilon$ & $v, \Lambda$ & $7, \mathrm{~V}$ & 6.9 \\
\hline
\end{tabular}


J. Food and Dairy Sci., Mansoura Univ., Vol. 3 (7), July, 2012

Table (5): Effect of sweetener type on the physicochemical properties of the fermented permeate fruit ices.

\begin{tabular}{|c|c|c|c|c|c|c|c|c|c|c|c|c|}
\hline \multirow[b]{2}{*}{ Properties } & \multicolumn{4}{|c|}{ Kumquat } & \multicolumn{4}{|c|}{ Apricot } & \multicolumn{4}{|c|}{ Cantaloupe } \\
\hline & Control & Natreen & $\begin{array}{c}\text { Sweet } \\
\text { line }\end{array}$ & Steviapura & Control & Natreen & $\begin{array}{c}\text { Sweet } \\
\text { line }\end{array}$ & Steviapura & Control & Natreen & $\begin{array}{c}\text { Sweet } \\
\text { line }\end{array}$ & Steviapura \\
\hline Total Solids & 32.35 & 8.34 & 8.34 & 8.34 & 33.09 & $9, \cdot 1$ & $9, \cdot 1$ & 9.08 & $r \uparrow, \wedge 0$ & $V, V \Psi$ & $V, V T$ & 7.73 \\
\hline $\mathrm{pH}$ & $\varepsilon, \Gamma \varepsilon$ & $\varepsilon, \Gamma T$ & $\varepsilon, \Gamma$ & 4.32 & $T, \pi$ & $T, T V$ & $r, T V$ & 3.65 & $\varepsilon, \varepsilon \wedge$ & $\varepsilon, \wedge \uparrow$ & 4.89 & 4.84 \\
\hline Specific Gravity &., 910. & 0.842 & 0.828 & 0.843 & 0.757 & $\cdot, 707$ & $\cdot, 771$ & 0.667 & 0.783 & 0.717 & 0.761 & 0.752 \\
\hline $\begin{array}{c}\text { Weight per } \\
\text { Kilogram }(\mathrm{W} / \mathrm{K})\end{array}$ & $r, q \vee 7$ & 3.658 & $r, 09 \lambda$ & 3.623 & $r, r \wedge q$ & $r, \wedge 0$ & $r, q \cdot r$ & 2.891 & $r, \varepsilon \cdot r$ & 3.115 & $r, \varepsilon r V$ & 3.423 \\
\hline Overrun (\%) & 34.21 & 23.52 & 23.24 & 23.24 & 31,07 & $Y Y, Y \leqslant$ & $r 1, \varepsilon r$ & 22.42 & ro, qV & 34.67 & $3 \leqslant, 0$ & 33.4 \\
\hline $\begin{array}{l}\text { Melting } \\
\text { resistance }\end{array}$ & & & & & & & & & & & & \\
\hline After $0.5 \mathrm{hr}$. & 99,99 & 99,99 & 99,97 & 99.99 & $9 V, 7 V$ & 99,99 & $1 \ldots$ & 99.99. & 99,91 & 99,91 & $1 \ldots$ & 99.98 \\
\hline After $1.0 \mathrm{hr}$. & $9 \lambda, \vee \leqslant$ & $9 \wedge, \vee 1$ & $99,9 V$ & 99.98 & $\Lambda V, \wedge O$ & $9 V, \leqslant \leq$ & $9 \Lambda, V$ & 98.93 & $9 V, 01$ & 99,91 & 99,99 & 99.82 \\
\hline After $1.5 \mathrm{hr}$. & $11, \cdot 1$ & $9 \pi, r_{0}$ & $q_{\cdot}, \wedge \leqslant$ & 91.23 & $T 1, Y Y$ & $N r, 10$ & N1,Or & 83.46 & $\vee ৭, \wedge \wedge$ & $\Delta 4,1$ & $\wedge q, \cdot V$ & 89.34 \\
\hline Energy (kcal.) & $1 \cdot 1,1$. & $\Lambda, 1$ & $\Lambda, 1$ & $\Lambda, 1$ & $\| r, V$ & $M r, V$ & $I r, V$ & $I r, V$ & $97, \nvdash \wedge$ & $17, Y 1$ & $17, Y \wedge$ & $17, Y \wedge$ \\
\hline
\end{tabular}


J. Food and Dairy Sci., Mansoura Univ., Vol. 3 (7): 431 - 446, 2012

Table (6): Effect of sweetener type on the sensory evaluation of the fermented permeate fruit ices

\begin{tabular}{|c|c|c|c|c|c|c|c|c|c|c|c|c|}
\hline \multirow[b]{2}{*}{ Properties } & \multicolumn{4}{|c|}{ Kumquat } & \multicolumn{4}{|c|}{ Apricot } & \multicolumn{4}{|c|}{ Cantaloupe } \\
\hline & Control & Natreen & $\begin{array}{l}\text { Sweet } \\
\text { line }\end{array}$ & $\begin{array}{c}\text { Stevia } \\
\text { pura }\end{array}$ & Control & Natreen & $\begin{array}{c}\text { Sweet } \\
\text { line }\end{array}$ & $\begin{array}{c}\text { Stevia } \\
\text { pura }\end{array}$ & Control & Natreen & $\begin{array}{c}\text { Sweet } \\
\text { line }\end{array}$ & $\begin{array}{c}\text { Stevia } \\
\text { pura }\end{array}$ \\
\hline Flavour(50) & $\sum 9$ & $\sum 9$ & $\sum 9$ & 49 & $\sum \Lambda$ & $\sum \wedge$ & $\sum \wedge$ & 48 & £o & $\varepsilon r$ & $\varepsilon r$ & 43 \\
\hline $\begin{array}{c}\text { Body\& } \\
\text { Texture(40) }\end{array}$ & rq & rᄉ & rᄉ & 38 & ru & rV & rV & 37 & $r V$ & ry & ry & 36 \\
\hline Melting(10) & 9 & $\Lambda$ & $\wedge$ & 8 & 9 & $\Lambda$ & $\Lambda$ & 8 & $\Lambda$ & $\Lambda$ & $\Lambda$ & 8 \\
\hline Total(100) & $9 V$ & 90 & 90 & 95 & 90 & 94 & 94 & 93 & 9. & $\wedge V$ & $\Lambda V$ & 87 \\
\hline
\end{tabular}


J. Food and Dairy Sci., Mansoura Univ., Vol. 3 (7): 431 - 446, 2012 